\title{
Alcohol and Handwritings
}

\section{Ayushi Rana ${ }^{1 *}$ Mahendra Verma ${ }^{2}$ and Munish Mishra ${ }^{3}$}

\author{
${ }^{1}$ Assistant Professor, Nims University, Jaipur, Rajasthan, India \\ ${ }^{2}$ Principal, Nims Paramedical Jaipur, India \\ ${ }^{3}$ Assistant Professor, Allahabad, India
}

Check for updates

Received: 31 August, 2021

Accepted: 20 September, 2021

Published: 21 September, 2021

*Corresponding author: Ayushi Rana, Assistant Professor, Nims University, Jaipur, Rajasthan, India, Email: ayushisingh1183@gmail.com, tanyasingh1183@ gmail.com

Keywords: Handwriting; Influence of alcohol; Neurological disruption; Handwriting variations

Copyright: @ 2021 Rana A, et al. This is an openaccess article distributed under the terms of the Creative Commons Attribution License, which permits unrestricted use, distribution, and reproduction in any medium, provided the original author and source are credited.

https://www.peertechzpublications.com

\section{Abstract}

Handwriting requires coordination of motor skills and cognitive skills which reflects the pictorial effect of the writer and their social and cultural patterns. It creates a unique combination of graphics and motor control of hands which is accepted by the society. Personality traits and characteristics are defined and have the unique handwriting, which gives the writer its individuality. Every writer is individual in their own way based on the handwriting features which can undergo variation when the writer shows commotion and disruptions in its normal neurological and muscular control. This paper reviews and focuses on the natural variation of the writing and also if these variations are caused under the influence of any externally induced elements, such as alcohol.

\section{Introduction}

Handwriting is an important factor of analysis in the criminal offences as it gets disguised in forgeries and precisely for this reason, it is an interesting subject of study for the experts. The forger tries to forge the handwriting by various process. Handwriting is a neuromuscular task which comes from the mind as mental pictures, but the term originates here as a natural variation which differentiate each writer as it does not allow duplication and each writing is authenticated and unique for the writer.

The questioning occurs just to find out neuromuscular authenticity in case if the person claims that this writing does not belong to him/her. In such cases the features of handwriting are analyzed for the class characteristics to find out the forgers based on conclusive forensics opinion [1]. Handwriting is based on the fact that no two individual can have the same writing [2]. Examiners follow certain rules to draw attention on the key features to analyze the writing and the writers $[3,4]$.

Handwriting analysis involves comprehensive comparative analysis of questioned documents and known handwriting suspected specimen they analyzed through the similarities and differences [4,5]. This follows steps such as analysis of the known writing samples and unknown sample for distinguishing features. The next step is drawing the comparison to differentiate the known material from the unknown which identify grammar, punctuation marks spelling and then evaluation which is done to understand the similarities of those features from matched to unmatched samples [2]. Handwriting changes and shows variation due to many reasons where the influence of alcohol can be a major cause of discrepancy. When the person is inebriated, the neurologicalmotor movements loses muscular coordination from the hands and the handwriting changes under the effect of intemperance [6]. The penmanship is analyzed by comparing the questioned and standard writing for class characteristics and individual characteristics.

Some of the significant class characteristics comprise alignment, size, line quality, slant, spacing rhythm and individual features that include the connecting strokes, embellishment, terminal strokes after analyzation of these characteristics [6]. The pictorial writer can be identified in writing in a two-way circuit, where mind gives instruction to hands and hands present the mental picture through fingers on the papers. 
As per the categorization provided in the literature [6], especially in the Type-0-25\% blood alcohol concentration vol./vol., in the preliminary examination of the handwriting samples, eleven features have been identified, which are as follows:

1. Rhythm: Rhythmic/Non Rhythmic.

2. Word alignment: Even Absent.

3. Pictorial effect: Skilled/Unskilled

4. Spacing: Present/Absent.

5. Misspelling: Present/Absent.

6. Tremors: Present/Absent.

7. Connecting Strokes: Connected/Disconnected

8. Line Quality: Good/Poor/Smooth.

9. Hesitation: Present/Absent

10. Size: Small/Large/Medium.

\section{Slant: Left/Right/Vertical}

Table 1 displays the frequency of the occurrence of affected features of handwriting at different alcoholic level for a sample of $n-30$. The eleven features were selected to analyze the natural variation of the handwriting in their intoxicated stage at different alcoholic level of the writer.

When the same data is subjected to Chi square test for analysis and interpretation, the following picture emerges, as is reflected in Table 2 .

\section{Discussion}

These Chi Square value data suggests the differences in the natural variation of these handwriting features as after the intoxication few features have been found to be affected such as significant spacing, pictorial effects, misspelling, hesitation, line quality, rhythm, alignment, tremor, etc.

Table 1: Frequency of Occurrence of Affected Feature.

\begin{tabular}{|c|c|c|}
\hline S.NO & Features & Blood Alcohol Concentration (0-25\%) \\
\hline 1 & Slant & 6 \\
\hline 2 & Tremor & 4 \\
\hline 3 & Connecting Strokes & 22 \\
\hline 4 & Alignment & 19 \\
\hline 5 & Size & 19 \\
\hline 6 & Spacing & 23 \\
\hline 7 & Pictorial Effect & 22 \\
\hline 8 & Misspelling & 12 \\
\hline 9 & Hesitation & 23 \\
\hline 10 & Line Quality & 23 \\
\hline 11 & Rhythm & 24 \\
\hline
\end{tabular}

Source: Data collected by the Researcher
Table 2: Chi-Square Analysis of the Occurrence and Its Interpretation.

\begin{tabular}{|c|c|c|c|}
\hline S.NO & Features & Chi Square Value & Interpretation \\
\hline 1 & Slant & 0.32 & Not significant \\
\hline 2 & Tremor & 5.3 & Significant \\
\hline 3 & Connecting Strokes & 0.98 & Not significant \\
\hline 5 & Alignment & 5.78 & significant \\
\hline 6 & Size & 0.32 & Not significant \\
\hline 7 & Spacing & 5.12 & significant \\
\hline 8 & Pictorial Effect & 9.68 & significant \\
\hline 9 & Misspelling & 4.58 & significant \\
\hline 10 & Hesitation & 9.68 & significant \\
\hline 11 & Line Quality & 5.12 & significant \\
\hline
\end{tabular}

Source: Data collected by the Researcher

These are the features evident post alcohol ingestion whereas connecting strokes, size do not favor any change in individuals. What has been concluded that in those persons in whom the blood alcohol concentration vol/vol is $0-25 \%$, they display the following features affected [6]. When the blood analyzer is found to test the person after intoxication, handwriting have been found to be displaying few changes in the handwriting, which undergoes differentiation. These features, due to lack of muscular control and coordination, resulting in poor execution of letters which leads to clumsiness, lack of smoothness in the letter size and shape of the pictorial skills of the writer [710]. It is also concluded that the writers are ill mannered as commanding authority brain loses its control over the motor movements, and the shape and size speed changes of the hands. It is found that handwritings are arranged mentally and performed neuro-muscularly, which gets affected during alcohol intakes, leading to cognitive and psychomotor effects.

\section{Conclusion}

This study was conducted on a population of 100, and subsequently 30 samples subject which gave the result that alcohol consumption has significant effect on handwriting misspelling, hesitation, rhythm, line quality, tremors and size in the handwriting of the individuals in their pre and post intoxicated stage. However, the formation and other internal characteristics remain similar independent of intoxication.

\section{References}

1. Briggs ME (2002) Empirical Study, Writer Identification: Determination of Gender from Check Writing Style. Journal of Question Document Examination 10 $3-21$.

2. Bertolini D, Oliveira LS, Justino E, Sabourin R (2012) Textured Based Descriptors for Writer Identification and Verification. Expert System with Applications 40: 2069-2080. Link: https://bit.ly/3Ctb67n

3. Cha SH, Tappert CC (2002) Automatic Detection of Handwriting Forgery Proceedings of the $8^{\text {th }}$ International Workshop on Frontiers in Handwriting Recognition (IWFHR). Canada 264-267. Link: https://bit.ly/2Z8G1r7

4. Chun CH (2003) Forged Handwriting Detection. M.S. Dissertation School of CSIS, Pace University. 
5. Beck J (1995) Sources of Error in Forensic Hand Writing Evaluation. Journal of Forensic Sciences 40: 31. Link: https://bit.ly/3tRjU3S

6. Asicioglu F, Turan N (2003) Hand Writing Changes Under the Effect of Intoxication. Journal of Forensic Science.

7. Epstein G (1987) Examination of the Josef Mengele handwriting. Journal of Forensic Science 32: 100-109. Link: https://bit.ly/3nPT2jy
8. Dvorsak Ann (2010) Rubber Stamp Fake or Genuine? How to Distinguish the Fake from the Genuine, Slovenian Manual for Private Detective.

9. Fisher J, Maredia A, Nixon A, Williams N, Leet J (2012) Identifying Personality Traits and Especially Traits Resulting in Violent Behavior through Automatic Handwriting Analysis. Center for strategic and International studies 132: 201210. Link: https://bit.ly/3u7LOZH

10. Osborn AS (1929) Questioned Document, Wigmore Boyd Pr. Albany, N.Y.
Discover a bigger Impact and Visibility of your article publication with

Peertechz Publications

\section{Highlights}

* Signatory publisher of ORCID

* Signatory Publisher of DORA (San Francisco Declaration on Research Assessment)

* Articles archived in worlds' renowned service providers such as Portico, CNKI, AGRIS, TDNet, Base (Bielefeld University Library), CrossRef, Scilit, J-Gate etc.

* Journals indexed in ICMJE, SHERPA/ROMEO, Google Scholar etc.

* OAI-PMH (Open Archives Initiative Protocol for Metadata Harvesting)

* Dedicated Editorial Board for every journal

* Accurate and rapid peer-review process

* Increased citations of published articles through promotions

* Reduced timeline for article publication

Submit your articles and experience a new surge in publication services

(https://www.peertechz.com/submission).

Peertechz journals wishes everlasting success in your every endeavours. 